\title{
Mycoplasma pneumoniae pneumonia revisited within the German Competence Network for Community-acquired pneumonia (CAPNETZ)
}

\author{
Heike von Baum*1, Tobias Welte ${ }^{2}$, Reinhard Marre ${ }^{3}$, Norbert Suttorp ${ }^{4}$, \\ Christian Lück ${ }^{5}$ and Santiago Ewig 6
}

\begin{abstract}
Address: ${ }^{1}$ Institute. for Medical Microbiology and Hygiene, Ulm University Hospital, Ulm, Germany, ${ }^{2}$ Department of Pneumonology, Hannover University Hospital, Hannover, Germany, ${ }^{3}$ Hospital Administration, Ulm University Hospital, Ulm, Germany, ${ }^{4}$ Department of Infectious Diseases and Pulmonary Medicine, Charité, Berlin, Germany, ${ }^{5}$ Institute of Med. Microbiology and Hygiene, Dresden University Hospital, Dresden, Germany and ${ }^{6}$ Department of Pneumonology, Thoraxzentrum Ruhrgebiet, Herne und Bochum, Germany

Email: Heike von Baum* - heike.von-baum@uniklinik-ulm.de; Tobias Welte -welte.tobias@mh-hannover.de; Reinhard Marre - reinhard.marre@uniklinik-ulm.de; Norbert Suttorp - norbert.suttorp@charite.de; Christian Lück - christian.lueck@tudresden.de; Santiago Ewig - ewig@augusta-bochum.de

* Corresponding author
\end{abstract}

Published: 13 May 2009

BMC Infectious Diseases 2009, 9:62 doi:10.1 I86/1471-2334-9-62
Received: 20 August 2008

Accepted: 13 May 2009

This article is available from: http://www.biomedcentral.com/I47I-2334/9/62

(C) 2009 von Baum et al; licensee BioMed Central Ltd.

This is an Open Access article distributed under the terms of the Creative Commons Attribution License (http://creativecommons.org/licenses/by/2.0), which permits unrestricted use, distribution, and reproduction in any medium, provided the original work is properly cited.

\begin{abstract}
Background: Currently, broad empiric antimicrobial treatment including atypical coverage is recommended for patients with mild to moderate community-acquired pneumonia (CAP). Therefore, the relative impact of each atypical pathogen, particularly Mycoplasma pneumoniae deserves renewed attention.
\end{abstract}

Methods: Based on prospective data from 4532 patients with CAP included in the German CAPCompetence Network (CAPNETZ), we studied the incidence, clinical characteristics, and outcome of patients with Mycoplasma pneumoniae pneumonia (MPP). The diagnosis of MPP was based on a positive PCR from respiratory samples and/or a positive IgM-titer from an acute phase serum sample.

Results: 307 patients (6.8\%) had definite MPP (I48 with positive PCR, 204 with positive IgM, 46 with positive PCR and (gM). Compared to patients with other definite and unknown etiologies, patients with MPP were significantly younger ( $41 \pm 16$ versus $62 \pm 17$ and $61 \pm 18$ years), had fewer co-morbidities, presented with a less severe disease, showed a lower inflammatory response in terms of leukocyte counts (median 8850 versus 13200 and II $1000 \mu \mathrm{L}$ ) and CRP values (60 versus 173 and $73 \mathrm{mg} / \mathrm{L})$, and had better outcomes, including a shorter length of hospitalization $(9 \pm 5$ versus $14 \pm 1 \mathrm{I}$ and $12 \pm 9$ days), fewer patients requiring mechanical ventilation ( 0.3 versus 4.5 and $2.1 \%$ ), and a minimal mortality ( 0.7 versus 8.7 and $6.5 \%$ ).

Conclusion: In this large series of patients with definite MPP according to very strict criteria, MPP appears as a condition with a high incidence, quite specific clinical presentation, and a largely benign course. In view of a widely favorable clinical outcome, recent recommendations including regular coverage of atypical pathogens in patients with mild to moderate CAP might be reconsidered for patients in Germany as well as in other countries with comparable epidemiological settings. 


\section{Background}

Mycoplasma pneumoniae as an important pathogen of community-acquired pneumonia (CAP) is only rarely diagnosed in routine practice. This is explained by the many limitations of paired serology which still is the applied diagnostic tool in most cases. In several epidemiologic studies of CAP, largely relying on paired serology, Mycoplasma pneumoniae was identified in 5-15\% of cases, resulting in a second or third rank pathogen causing CAP in most series [1,2]. Together with Legionella spp. and Chlamydophila pneumoniae, these three pathogens are usually addressed as "atypical bacterial pathogens", and considered as prominent targets for broad spectrum antimicrobial treatment including atypical coverage [3].

This approach is questionable for several reasons. First, it may discourage clinical services to include microbial investigations in their diagnostic work-up and thereby promote the decline of any effort to design targeted antimicrobial treatment. Second, relying on paired serology for the diagnosis of MPP necessarily misses acute deaths from pneumonia, and may thereby provide misleading clinical descriptions of the disease and underestimate the prognostic implications of this pathogen. Finally, lumping together all three atypical pathogens throughout all pneumonia severities at admission may heavily bias the potential prognostic implications of the pathogens included in this group, and thereby lead to recommendations of initial empiric antimicrobial treatment implying frank overtreatment.

For these reasons, based on the large CAPNETZ database, we aimed at identifying patients with CAP due to Mycoplasma pneumoniae using a very strict methodology, in order to revisit the epidemiology, clinical characteristics, and the outcome of these patients. In addition, we thought to reconsider the recommended diagnostic approach to atypical pathogens on the background of our findings.

\section{Methods \\ Patient Population}

A detailed description of the CAPNETZ methodology is given elsewhere [4]. In short, the inclusion criteria for the CAPNETZ study were age $\geq 18$ years, the presence of a new infiltrate in chest radiography, and at least one of the following criteria: history of fever $\left(\geq 38.3^{\circ} \mathrm{C}\right)$, cough, presence of purulent sputum or focal chest signs on auscultation. Patients who had been hospitalized during 28 days preceding the study, with severe immunosuppression or active tuberculosis were excluded.

The study was approved by the ethical review board, and all patients included gave informed consent.

\section{Data Collection}

In this prospective study, all demographic, clinical and diagnostic data of the patients were recorded using standardized web-based data sheets created by $2 \mathrm{mt}^{\circledR} \mathrm{Ulm}$, Germany. The study period comprised 55 months starting on $1^{\text {st }}$ June 2002 and ending 31 ${ }^{\text {st }}$ December 2006, thus including almost five autumn-winter seasons.

\section{Microbiological Processing and Examination}

Physicians were asked to provide a sputum sample from all study patients. However, if the patient was not able to produce a sputum sample, it was the physician's decision to perform more invasive procedures. Methods applied were described previously [5]. In short, sputum and/or other respiratory secretions were immediately processed in the participating local microbiological laboratories according to the German Quality Standards in Clinical Microbiology and Infectious Diseases MIQ [6]. The results of virus testing are not included in this report.

\section{Investigation for Mycoplasma pneumoniae and case definition for Mycoplasma pneumonia}

Respiratory specimens and acute-phase serum were collected, stored frozen for a maximum time period of 3 months and then sent to the central service unit in Ulm on dry ice. After arrival at the central service unit completeness of the number and kind of specimens was checked and specimens were stored at $-80^{\circ} \mathrm{C}$. Both respiratory specimen as well as sera were analysed retrospectively. Physicians were not aware of the test results in time to change therapy. The DNA from the clinical samples was extracted by using the QIAamp DNA Mini Kit (Qiagen, Hilden, Germany) according to the manufacturer's instructions [7].

Detection of Mycoplasma DNA from respiratory samples was performed in the Institute for Medical Microbiology and Hygiene, Dresden, the German Consulting Laboratory for Mycoplasma pneumoniae by using a real-time PCR targeting the inter-repetitive region of the $\mathrm{P} 1$ gene. We used an antigen enriched with P1 (160 KD) mature adhesin. The real-time PCR readily detects all subtypes and variants of Mycoplasma pneumoniae with a detection limit of approximately 10 genomic equivalents [8]. To exclude an inhibition each sample was spiked with 1000 DNA copies and retested under the same conditions.

For the detection of Mycoplasma pneumoniae-specific IgG, IgA or IgM antibodies the Virotech EIA (Genzyme Virotech, Russelsheim, Germany) was used according to the manufacturer's instructions. The EIA is based on a defined antigen mix that includes the P1, P100, and P30 proteins.

In the present study, definite Mycoplasma pneumonia was defined as: 1) a positive PCR based detection of Myco- 
plasma pneumoniae DNA in respiratory samples or 2) a positive IgM test in the acute phase serum sample.

\section{Statistical analysis}

Comparisons between groups were performed by means of the Chi square test for categorical variables or analysis of variances (ANOVA) for continuous variables including multiple comparisons. All analyses were performed with SPSS software (SPSS 10.0, Chicago, IL). All tests of significance were 2-tailed, and alpha was set at 0.05 . To correct for multiple testing the Bonferroni correction was applied to the variables presented in table 1 and the significance level was consecutively set as $\mathrm{p}<.001$.

\section{Results}

General characteristics of study population

Overall, 4532 patients with CAP from twelve clinical centers throughout Germany were included in our analysis. The 2492 male and 2040 female patients had a mean age of $60 \pm 19$ years. Sixty-five percent $(n=2922)$ of the patients were hospitalized when first contacted for participation in CAPNETZ. Co-morbidities were present in 2565 patients (57\%). Thirty-one percent of the patients were smokers. Fifty-six percent of all patients presented with fever, 92\% coughed, 73\% had dyspnoea, and 8\% showed signs of confusion. 106 patients $(2.3 \%)$ required mechanical ventilation and 290 patients (6.4\%) died (30 day mortality). The demographic and clinical data of the patients are given in Table 1.

Diagnosis and epidemiology of Mycoplasma pneumonia Respiratory samples were available from 1538 (33.6\%) of the patients (Table 2). 148 (9.6\%) of patients with respiratory samples had a positive Mycoplasma pneumoniae PCR.

Acute serum samples were available in 4450 patients. Altogether 204 (4.6\%) patients had Mycoplasma pneumoniae-specific IgM antibodies in the acute phase serum sample. 46 patients were positive in both PCR and IgM antibody assay. Thus, 159 additional cases of Mycoplasma pneumoniae infection were identified by $\operatorname{IgM}$ antibody detection.

Taken together, 307 patients (6.8\%) were considered as having definite Mycoplasma pneumonia (Table 2).

In support of our working definition, patients with a positive PCR from respiratory samples had almost identical characteristics if compared to patients with a positive IgM serum test, whilst patients with a positive IgA or IgG serum test were older, predominantly men, more often hospitalized, had higher CRB-65 scores and a fatality rate of $7.5 \%$ and $6.3 \%$, respectively (Table 3 ).

\section{Clinical characteristics of patients with CAP caused by Mycoplasma pneumoniae}

Patients with Mycoplasma pneumonia were significantly younger than any other group of CAP patients with definite or unknown etiology in the study population (Figure 1) and clearly had fewer co-morbidities. The severity of their pneumonia was much lower as reflected by a high number of patients with low CRB-65 scores and a significantly lower inflammatory response as reflected by median leukocyte counts and CRP values on admission (Table 1). There were no statistically significant differences for the variables smoker, fever, cough, new auscultatory findings or chronic liver disease. In addition, though not statistically significant only one patient had to be mechanically ventilated and the length of hospitalization was significantly lower. The fatality rate was very low $(0.7 \%)$ and significantly different if compared to the groups with another definite or unknown etiology, respectively.

Mixed infections of Mycoplasma pneumoniae with other bacterial pathogens were present in 20 cases; in particular Legionella spp. $(\mathrm{n}=8)$, Streptococcus pneumoniae $(\mathrm{n}=7)$, Haemophilus influenzae $(\mathrm{n}=3)$, and Staphylococcus aureus (MSSA) $(n=2)$. None of the patients with mixed infection died.

Of 307 patients with Mycoplasma pneumonia, 171 were treated as outpatients and 136 were hospitalized. The former group was even younger, had very mild pneumonia, had fewer diabetic patients and a milder inflammatory response. No outpatient died (Table 4).

\section{Antimicrobial treatment and outcome of patients with Mycoplasma pneumonia}

Detailed data concerning antimicrobial treatment were available for $97 \%$ of all patients. The predominant classes of antimicrobial agents administered were macrolides/ ketolides (37\%) and fluoroquinolones (29\%). Overall, $65 \%$ of patients with Mycoplasma pneumonia had received antimicrobial agents active against atypical bacteria. There was a trend for patients with Mycoplasma pneumonia receiving more often antimicrobial agents covering atypical bacteria than those with another bacterial or without established etiology. There was no statistically significant difference in outcome $(p=.11)$ or length of hospitalization $(\mathrm{p}=.057)$ between patients with $\mathrm{Myco}$ plasma pneumonia who received appropriate or inappropriate antibiotic therapy, respectively.

A 71-years old patient diagnosed by PCR died several hours after he had been admitted to the hospital. The cause of death was not established. An additional female patient, aged 69 years, died after 10 days of hospitalization. She suffered from COPD, was a heavy smoker and 
Table I: Clinical characteristics and antimicrobial treatment of patients with Mycoplasma pneumoniae pneumonia (MPP), CAP due to other bacterial pathogens, and CAP with unknown etiology

\begin{tabular}{|c|c|c|c|c|c|}
\hline Variable & $\begin{array}{l}\text { CAP due to other definite bacterial } \\
\text { pathogens } \\
n=621\end{array}$ & $\mathbf{p}^{\prime}$ & MPP $n=307$ & $\mathbf{p}^{2}$ & $\begin{array}{c}\text { CAP with no known bacterial } \\
\text { etiology } n=3604\end{array}$ \\
\hline Age $(\varnothing \pm S D)$ & $61 \pm 17$ years & .000 & $41 \pm 16$ years & .000 & $61 \pm 18$ years \\
\hline Male gender & $58 \%$ & .000 & $41 \%$ & .000 & $56 \%$ \\
\hline Outpatient/hospitalized & $22 \% / 78 \%$ & .000 & $56 \% / 44 \%$ & .000 & $36 \% / 64 \%$ \\
\hline $\begin{array}{l}\text { CRB } 65 \text { Score } \\
0-1-2-3-4(\%)\end{array}$ & $33-46-16-4-1$ & .000 & $72-25-3-0.4-0$ & .000 & $39-43-15-2-0.4$ \\
\hline $\operatorname{Packyears}(\varnothing \pm S D)$ & $32 \pm 25$ & .000 & $15 \pm 14$ & .000 & $29 \pm 23$ \\
\hline Pleural effusion & $17 \%$ & .000 & $6 \%$ & .001 & $13 \%$ \\
\hline Dyspnoea & $80 \%$ & .000 & $69 \%$ & ns & $72 \%$ \\
\hline Pleural pain & $47 \%$ & .000 & $34 \%$ & ns & $42 \%$ \\
\hline Confusion & $11 \%$ & .000 & $2 \%$ & .001 & $8 \%$ \\
\hline Oxygen requirement & $57 \%$ & .000 & $25 \%$ & .000 & $41 \%$ \\
\hline Malignancy & $9 \%$ & .000 & $2 \%$ & .000 & $10 \%$ \\
\hline Chronic respiratory disease & $38 \%$ & .000 & $20 \%$ & .000 & $36 \%$ \\
\hline Renal insufficiency & $8 \%$ & .001 & $2 \%$ & .000 & $8 \%$ \\
\hline Congestive heart failure & $19 \%$ & .000 & $4 \%$ & .000 & $19 \%$ \\
\hline Diabetes & $20 \%$ & .000 & $3 \%$ & .000 & $16 \%$ \\
\hline Respiratory sample obtained* & $42 \%$ & .000 & $58 \%$ & .000 & $30 \%$ \\
\hline Leucocytes (median) $/ \mu \mathrm{l}$ & 13200 & .000 & 8850 & .000 & 11000 \\
\hline CRP (median) mg/l & 173 & .000 & 60 & .001 & 73 \\
\hline $\begin{array}{l}\text { Duration of antibiotic therapy } \\
(\varnothing \pm S D)\end{array}$ & $13 \pm 6$ days & .000 & $1 \mathrm{I} \pm 4$ days & ns & $11 \pm 5$ days \\
\hline $\begin{array}{l}\text { LOS in hospitalized patients } \\
(\varnothing \pm \text { SD) }\end{array}$ & $14 \pm 1$ I days & .000 & $9 \pm 5$ days & .000 & $12 \pm 9$ days \\
\hline Deaths within 30 days & $54(8.7 \%)$ & .000 & $2(0.7 \%)$ & .000 & $234(6.5 \%)$ \\
\hline
\end{tabular}

Patients with Mycoplasma pneumonia (MPP) were compared to patients with CAP due to other bacterial pathogens ( $P$ values marked as $\left.P^{\prime}\right)$ and patients with CAP with unknown etiology ( $p$ values marked as $\mathrm{p}^{2}$ ), respectively. The significance level was set at $<.001$. $(*)$ samples were available for standardized examination in the CAPNETZ central study unit. SD = standard deviation ns $=$ not significant 
Table 2: Diagnosis of Mycoplasma pneumonia in 4532 adult patients with community acquired pneumonia

\begin{tabular}{lcc}
\hline Method & Samples tested & Samples with positive test result \\
\hline PCR from respiratory material & 1538 & $148(9,6 \%)$ \\
\hline Sputum & 1335 & $134 *(10,1 \%)$ \\
\hline Broncho-alveolar lavage & 67 & $8(11,9 \%)$ \\
\hline Others (Throat washings) & 136 & $6 *(4,4 \%)$ \\
\hline
\end{tabular}

\begin{tabular}{lcc}
\hline IgM-Antibody EIA & 4450 & $204(4,6 \%)$ \\
\hline $\lg$ A-Antibody EIA & 4450 & $881(19,8 \%)$ \\
\hline $\lg$ G-Antibody EIA & 4450 & $1042(23,4 \%)$ \\
\hline
\end{tabular}

\begin{tabular}{lr}
\hline PCR from respiratory material + serum & 1448 \\
PCR positive + IgM-antibody positive & $46(3.2 \%)$ \\
PCR positive + IgA-antibody positive & $55(3.7 \%)$ \\
PCR positive + lgG-antibody positive & $69(4.7 \%)$ \\
\hline
\end{tabular}

\begin{tabular}{lc} 
PCR from respiratory material + serum & 1448 \\
PCR negative + IgM-antibody positive & $31(2.1 \%)$ \\
PCR negative + lgA-antibody positive & $246(17 \%)$ \\
PCR negative + lgG-antibody positive & $272(18.8 \%)$ \\
\hline
\end{tabular}

* 5 samples were inhibited

** 2 samples were inhibited

had to be mechanically ventilated. Both patients had not received antibiotics active against atypical bacteria.

\section{Discussion}

The main findings of our study, based on very strict diagnostic criteria in a large population of patients with CAP, can be summarized as follows: 1) Mycoplasma pneumoniae is an important pathogen causing CAP 2) patients with MPP are characterized by a quite specific clinical pattern, including younger age, absent or limited co-morbidity, limited inflammatory response, and usually presented with a mild to moderate pneumonia; 3 ) as a consequence, the majority of patients were treated as outpatients, hospitalized patients had a shorter length of stay, and mortality was minimal; 4) patients with Mycoplasma pneumonia treated as outpatients had even milder pneumonia than those hospitalized; 5) although there was a trend for patients with Mycoplasma pneumonia receiving antimicrobial drugs active against atypical bacterial pathogens more frequently than those with other or unknown etiologies, the rate of discordant treatment remained high.

This study is unique for the strict criteria for the diagnosis of Mycoplasma pneumonia and the large number of patients identified by this diagnostic approach. It is also unique for offering an identical extensive microbiological workup for hospitalized as well as outpatients. The incidence of Mycoplasma pneumoniae pneumonia was $6.7 \%$, which is at the lower range of previous figures reported in recent large etiologic studies.

Previous series of patients with CAP due to Mycoplasma pneumoniae have largely relied on serologic testing, either using paired serum samples or including IgM and/or acute IgG or IgA [9-14]. When designing our study it was decided - due to feasibility - to collect only one acute phase serum sample. This might be considered as a limitation of our study.

When considering our study patients with M.pneumoniae pneumonia we felt safe to designate patients with a positive PCR result from respiratory samples as a proven case of M.pneumoniae infection. Due to the fact that in many cases acute phase sera were available and serological tests had been performed, we then had a closer look at our serological test results to answer the question whether patients with a positive IgM for M.pneumoniae in their acute phase serum might be considered as proven cases of 
Table 3: Comparison of Mycoplasma pneumonia with positive PCR from respiratory samples to patients with positive serology results

\begin{tabular}{|c|c|c|c|c|c|c|c|}
\hline Variables & $\begin{array}{c}\text { PCR positive } \\
n=148\end{array}$ & $\begin{array}{c}\text { Only IgM positive } \\
n=159\end{array}$ & p-value & $\begin{array}{c}\text { Only IgA positive } \\
n=826\end{array}$ & p-value ${ }^{2}$ & $\begin{array}{l}\text { Only IgG } \\
\text { positive } \\
n=973\end{array}$ & p-value ${ }^{3}$ \\
\hline Age $\geq 50$ years & $23.6 \%$ & $23.3 \%$ & .841 & $67.6 \%$ & .000 & $60.5 \%$ & .000 \\
\hline Male gender & $45 \%$ & $38 \%$ & .240 & $58 \%$ & .003 & $54 \%$ & .026 \\
\hline Smoker & $29 \%$ & $42 \%$ & .017 & $37 \%$ & .037 & $34 \%$ & .243 \\
\hline \multicolumn{8}{|l|}{ Initial treatment setting } \\
\hline -outpatient & $66 \%$ & $46 \%$ & .000 & $33 \%$ & .000 & $39 \%$ & .000 \\
\hline -hospitalized & $34 \%$ & $54 \%$ & & $67 \%$ & & $61 \%$ & \\
\hline Fever & $68 \%$ & $59 \%$ & .081 & $55 \%$ & .003 & $56 \%$ & .004 \\
\hline Confusion & $3 \%$ & $2 \%$ & .632 & $9 \%$ & .013 & $8 \%$ & .023 \\
\hline \multicolumn{8}{|l|}{ CRB 65 Score } \\
\hline 0 & $74 \%$ & $70 \%$ & .499 & $41 \%$ & .000 & $46 \%$ & .000 \\
\hline $1-2$ & $22 \% / 4 \%$ & $29 \% / 1 \%$ & & $42 \% / 13 \%$ & & $38 \% / 12 \%$ & \\
\hline $3-4$ & 0 & $1 \% / 0$ & & $2 \% / 1 \%$ & & $3 \% / 1 \%$ & \\
\hline Mechanical ventilation & 0 & I patient & .332 & 23 patients & .040 & 20 patients & .078 \\
\hline Died within 30 days & $\begin{array}{l}\text { I patient } \\
(0.7 \%)\end{array}$ & $\begin{array}{c}\text { I patient } \\
(0.6 \%)\end{array}$ & .963 & $\begin{array}{l}62 \text { patients } \\
(7.5 \%)\end{array}$ & .002 & $\begin{array}{l}61 \text { patients } \\
(6.3 \%)\end{array}$ & .006 \\
\hline
\end{tabular}

Patients with positive PCR were compared to IgM only (column p-values') positive patients, to patients with only positive IgA (column $\mathrm{p}$-values ${ }^{2}$ ) and patients with positive lgG only (column -values $^{3}$ ), respectively. Forty-six patients were positive in PCR and IgM, 55 patients were positive in $P C R$ and $\lg A$ and 69 patients were positive in PCR as well as in IgG.

M.pneumoniae infection as well. In fact, the detection of specific IgM antibodies is generally accepted as an indication of a recent infection. Two aspects persuaded us to follow this hypothesis:

(i) IgM antibodies to M.pneumoniae are only very rarely detected in the sera of healthy subjects. When evaluating the Virotech kit used in our study in blood donors and orthopaedic patients only 2 out of 602 patient samples were IgM positive $(0.3 \%)$, whereas IgA and IgG antibodies were detected in a significant number of healthy persons [[15], C. Lück, personal communication].

(ii) Patients with a positive PCR result had very similar demographic and clinical characteristics if compared to patients with IgM antibodies only. Especially if looking at the initial CRB65 score, the proportion of patients requiring mechanical ventilation and the outcome (Table 3), we assumed it might be justified to regard PCR as well as IgM only positive patients as an entity if discussing clinical characteristics and management.

We used a commercially available test that uses specific Mycoplasma pneumoniae proteins as antigens. Therefore, a high specificity might be assumed and was demonstrated in a recent publication [15]. The detection of Mycoplasma pneumoniae DNA has a high positive predictive value. Albeit a persistence of Mycoplasma pneumoniae DNA after infection or within the incubation time has been reported it is generally accepted that such events are very rare $(<0,5 \%)[16,17]$.

In one third of our MPP patients we found concordant positive PCR and positive IgM test results. The IgM EIA used showed a moderate sensitivity in sera collected in the acute phase [15]. Thus, it seems reasonable to assume that some of the PCR positive patients might not yet have developed IgM antibodies. On the other hand, PCR might 


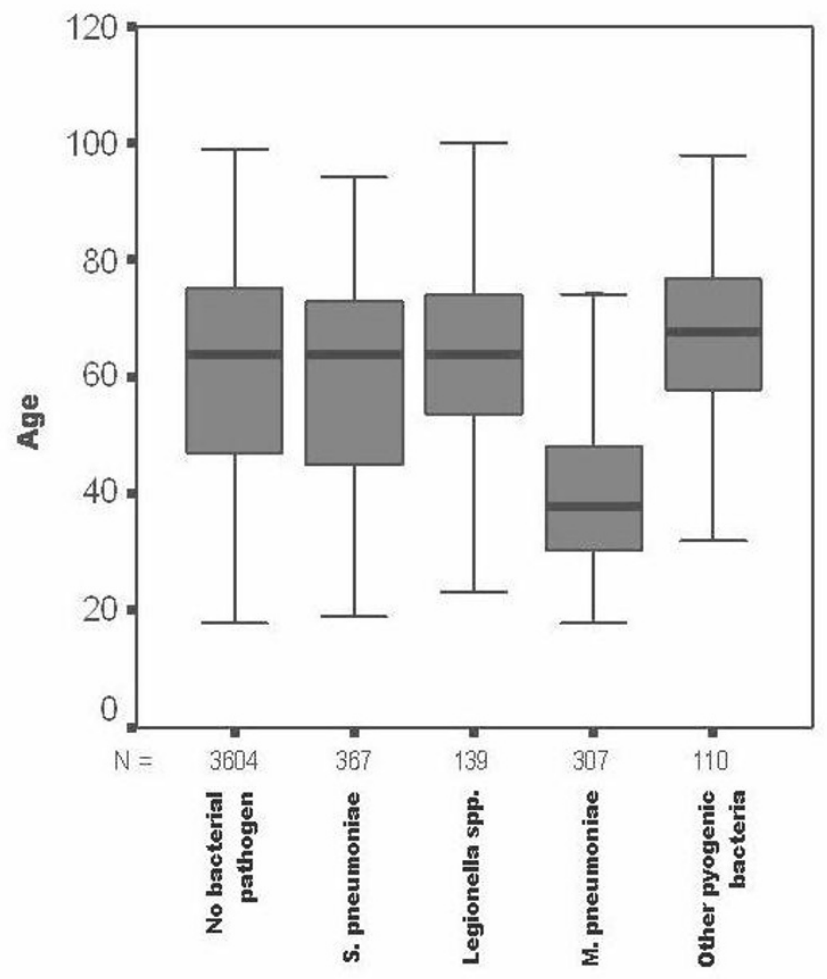

Figure I

Age distribution in 4527 patients with CAP. The data for five patients with CAP due to Chlamydophila pneumoniae and a mean age of $36.8 \pm 6.8$ years are not shown in this graph.

have resulted false-negative due to the detection limit of the PCR detection as well as the rapid elimination of $M y c$ oplasma pneumoniae after the initiation of antimicrobial treatment. In this context it should be noted that $27 \%$ of our patients received antibiotic agents at the time of inclusion into our study. The affection of antimicrobial treatment on clinical presentation and PCR or IgM responses in CAP caused by M.pneumoniae has never been studied to our knowledge. Therefore, we ignore the true effect of this confounder.

In contrast, clinical characteristics of patients with positive IgA titers were similar to that of patients with other bacterial and unknown etiologies but clearly different from the population with positive PCR and/or IgM, indicating that positive IgA titers represent persisting titers after infection occurring at any time. Moreover, the high prevalence of IgA antibodies (5-8\%) found in blood donors and patients without respiratory symptoms strongly indicates a poor specificity. Therefore, IgA antibody detection is of very limited use as a diagnostic tool of pneumonia due to Mycoplasma pneumoniae.
Despite our different and strict diagnostic approach based exclusively on real-time PCR in respiratory samples and acute phase IgM, our data confirm previous findings of MPP being associated with several peculiar clinical characteristics. Apart from Chlamydophila pneumoniae, Mycoplasma pneumoniae is the only bacterial respiratory pathogen clearly occurring more frequently in younger adults. In a large study on the etiology of CAP, Mycoplasma pneumoniae was the only age-associated pathogen [18]. It appears that it usually occurs before the forth decade. In this age class, it has been shown that Mycoplasma pneumoniae can result as the most frequent pathogen even prior to Streptococcus pneumoniae $[9,19]$. Probably as a consequence, patients with Mycoplasma pneumoniae have considerably fewer co-morbidities. The only concomitant disease occurring with a frequency of more than $10 \%$ in our MPP population was COPD.

Another important feature of MPP is its usually less severe presentation, both in terms of clinical CRB-65 severity scores as well as inflammatory response. None of the severe complications of Mycoplasma pneumoniae reported in the literature could be observed in our series [2], although it cannot be definitely excluded that we missed single cases with severe Mycoplasma pneumonia. In accordance with the regularly mild presentation of MPP, and in line with several previous reports, more than half of our patients were treated as outpatients, hospitalized patients had a shorter length of hospitalization, and mortality was very low [10-14]. Moreover, those treated as outpatients were even younger and presented with a milder pneumonia than those hospitalized (with 99\% having CRB-65 scores of less than 2).

Despite a trend for patients with MPP to receive more frequently antimicrobial treatment covering atypical bacterial pathogens, indicating that clinicians may have been aware of a probable Mycoplasma pneumonia, the rate of discordant treatment was high. Discordant treatment had no discernable effect on outcomes such as length of stay and mortality, indicating that MPP is usually a mild and self-limiting disease. Of note, however, both patients who died with MPP had received discordant treatment initially.

Our findings may have significant implications for future recommendations of empiric antimicrobial treatment in patients with CAP, particularly with respect to the need for covering atypical pathogens. If we consider Legionella spp., Mycoplasma pneumoniae and Chlamydophila pneumoniae as the three atypical bacterial pathogens treatable by antibacterial agents, it appears that only Legionella spp. are associated with a relevant mortality. In a recent series from our group, we could show that Legionella spp. was found with equal frequency in both ambulatory and hospitalized 
Table 4: Comparison of outpatients and hospitalized patients with Mycoplasma pneumoniae pneumonia

\begin{tabular}{|c|c|c|c|}
\hline Variable & $\begin{array}{c}\text { Outpatients } \\
N=17 \mid\end{array}$ & p value & $\begin{array}{c}\text { Hospitalized patients } \\
N=136\end{array}$ \\
\hline Age $[\varnothing \pm S D]$ & $38 \pm 13.1$ & .000 & $45 \pm 18.4$ \\
\hline Male gender & $44 \%$ & .320 & $38 \%$ \\
\hline \multicolumn{4}{|l|}{ CRB - 65 score } \\
\hline 0 & $79 \%$ & .002 & $64 \%$ \\
\hline $1-2$ & $20 \% / 1 \%$ & & $30 \% / 5 \%$ \\
\hline $3-4$ & 0 & & $1 \%-0$ \\
\hline Smoker & $39 \%$ & .185 & $32 \%$ \\
\hline COPD & $18 \%$ & .239 & $23 \%$ \\
\hline Diabetes & $0.6 \%$ & .013 & $5.1 \%$ \\
\hline Malignancy & $2 \%$ & .946 & $2 \%$ \\
\hline CRP median (mg/l) & 33 & .000 & 90 \\
\hline Leucocytes median $\left(10^{3} / \mu \mathrm{l}\right)$ & 7900 & .000 & 10300 \\
\hline Respiratory sample available & $68 \%$ & .000 & $46 \%$ \\
\hline Serum available & $98 \%$ & .112 & $94 \%$ \\
\hline Received antibiotic therapy active against atypical bacteria & $64 \%$ & .306 & $70 \%$ \\
\hline Length of antimicrobial therapy (days) & $10.6 \pm 4.1$ & .026 & $11.6 \pm 3.6$ \\
\hline Dyspnoea & $60 \%$ & .000 & $80 \%$ \\
\hline O 2 application & $2 \%$ & .000 & $55 \%$ \\
\hline Died (30 day mortality) & 0 & .112 & 2 patients \\
\hline
\end{tabular}

patients. However, severity was low and mortality was zero in ambulatory patients [5]. As a result, and in line with a recent meta-analysis of outcomes in non-severe CAP, atypical coverage does not seem to be relevant in terms of prevention of mortality in outpatients with CAP [20]. Following the definition of CAP used in our study we would advocate that in Germany as well as in other countries with comparable epidemiological settings a dual treatment with coverage of atypical pathogens as empirical standard therapy is not indicated for patients with mild CAP. However, antibiotic pneumococcal coverage continues to be the main demand in the treatment of this patient group.

Only recently, in a large study across four important world regions, Arnold et al. found a lower mortality in hospital- 
ized patients receiving atypical coverage. As a result, and referring to several other studies with similar findings, they strongly recommended such coverage in all hospitalized patients $[3,21,22]$. In their study, the global incidence of Legionella spp. was 5\%, of Chlamydophila pneumoniae 7\%, and of Mycoplasma pneumoniae $12 \%$. However, the rate of patients discharged alive at 14 and 30 days was not different but appeared only significantly different when the total number of patients discharged alive was considered, hinting at non-pneumonia-related reasons for different outcomes. Several other reports also do not support the conclusion of Arnold et al. [20,23-25]. Taking into account these reports and the present data, increased mortality in hospitalized patients with CAP is almost exclusively related to cases with moderate to severe pneumonia caused by Legionella spp. Another concern relates to mixed infections. In our series, the rate of mixed infections was low $(n=20)$, with no associated mortality. Most co-infections were caused by pneumococci and Legionella spp. which may be detected using routine diagnostic methods according to current ATS/IDSA recommendations [26]. Thus, a strategy of active search for patients with Legionella spp. or, in cases of more severe pneumonia, also for patients with Mycoplasma pneumoniae and Chlamydophila pneumoniae should obviate the need of regular atypical coverage in all hospitalized patients.

At present, we suggest that in hospitalized patients with CAP coverage of atypical bacteria can be limited to patients with severe CAP, those with confirmed legionellosis, Chlamydophila pneumoniae pneumonia and those with probable MPP, i.e. younger patients (age < 40 years) with absent or mild co-morbidity and a mild clinical presentation (CRB-65 < 2).

\section{Conclusion}

In conclusion, our study confirms previous reports about characteristic patterns of CAP through Mycoplasma pneumoniae. However, realizing the minimal risk of adverse outcomes associated with this condition, and having in mind recent findings of our group on legionellosis, atypical coverage of all patients presenting with mild CAP as defined in our study seems questionable. Instead, our data provide important hints for strategies aimed at a more judicious use of broad spectrum antimicrobial treatment with atypical coverage.

\section{Competing interests}

The authors declare that they have no competing interests.

\section{Authors' contributions}

$\mathrm{HvB}$ carried out analysis and interpretation of the data, performed the statistical analysis, participated in the coordination of the study and drafted the manuscript. TW participated in the design, coordination and supervision of the study as well as analysis and interpretation of the data, RM participated in the design, coordination and supervision of the study as well as analysis and interpretation of the data. NS participated in the design, coordination and supervision of the study. CL carried out all molecular and serological studies and participated in the analysis and interpretation of the data. SE participated in the analysis and interpretation of the data and drafted the manuscript. All authors read and approved the final manuscript.

\section{Acknowledgements}

CAPNETZ is a multidisciplinary approach to better understand and treat patients with community-acquired pneumonia. The network has only been made possible by the contribution of many investigators. We are especially indebted to the work of the investigators in the local clinical centres (LCC) who established and kept contact to all practitioners, physicians, and respiratory specialists cooperating within the network. Members of the CAPNETZ study group except the authors: F. Kunitz, M. Schmidt-loanas, H. Lode, T. Bauer (Center for Pneumology and Thoracic Surgery Heckeshorn, HELIOS Clinic Emil von Behring, Berlin), A. Kuhnke (Dept of Internal Medicine/Infectious Diseases and Pulmonary Medicine, Charite, Berlin), B. Schlosser, G. Rohde (Thoraxzentrum Ruhrgebiet, Dept of Respiratory Medicine and Infectious Diseases, Bochum), M. Pletz (Dept of Pneumology, University Clinic, Hannover), K. Dalhoff, S. Pischke, N. Schuebel (Dept of Medicine III, University of Luebeck), I.Huntemann, J. Lorenz (Luedenscheid), T. Klante (Magdeburg), T. Schaberg, K. Voigt (Rotenburg), S. Krueger, C. Schumann (Dept of Internal Medicine II, Ulm University Hospital, Ulm), B. Jany, U. Ziegler (Wuerzburg)

In addition, we would like to acknowledge the work of the central computing unit and the central service unit with Anna Sawazki providing excellent technical support.

It is also our responsibility and pleasure to express our appreciation to all clinical physicians and physicians in private practice who saw and identified patients with community acquired pneumonia for their work dedicated to CAPNETZ.

The network is supported by

German Ministry of Education and Research (Bundesministerium für Bildung und Forschung).

\section{References}

I. Foy HM: Infections caused by Mycoplasma pneumoniae and possible carrier state in different populations of patients. Clin Infect Dis 1993, I 7 Suppl I:37-46.

2. Waites KB, Talkington DF: Mycoplasma pneumoniae and its role as a human pathogen. Clin Microbiol Rev 2004, I 7:697-728.

3. Arnold FW, Summersqill JT, Lajoje AS, Pevrani P, Marrie TJ, Rossi P, Blasi F, Fernandez P, File TMJr, Rello J, et al.: A worldwide perspective of atypical pathogens in community-acquired pneumonia. Am J Respir Crit Care Med 2007, I 75:1086-93.

4. Welte T, Suttorp N, Marre R: CAPNETZ-community-acquired pneumonia competence network. Infection 2004, 32:234-38.

5. von Baum H, Ewig S, Marre R, Suttorp N, Gonschior S, Welte T, Lück C, Competence Network for Community-Acquired Pneumonia Study Group: Community Acquired Legionella Pneumonia - New Insights from the German competence network CAPNETZ. Clin Inf Dis 2008, 46: I 356-64.

6. Mauch H, Wagner J, Marklein G, Kühnen E, Albert S, Schuster L, Freidank H, Molitor E, Müller K-D, Kästli K, et al.: MIQ 7\&8. Infektionen der tiefen Atemwege Teil I und II. Qualitätsstandards in der mikrobiologisch-infektiologischen Diagnostik. GustavFischer-Verlag; Jena, Germany; 1999. 
7. Wellinghausen N, Straube E, Freidank $H$, von Baum H, Marre R, Essig A: Low prevalence of Chlamydia pneumoniae in adults with community-acquired pneumonia. Int J Med Microbiol 2006, 296:485-9l.

8. Dumke R, Schurwanz N, Lenz M, Schuppler M, Lück C, Jacobs E: Sensitive detection of Mycoplasma pneumoniae in human respiratory tract samples by optimized real-time PCR approach. J Clin Microbiol 2007, 45:2726-30.

9. Berntsson E, Blomberg J, Lagergard T, Trollfors B: Etiology of community-acquired pneumonia in patients requiring hospitalization. Eur J Clin Microbiol 1985, 4:268-72.

10. Woodhead MA, Macfarlane JT: Comparative clinical and laboratory features of legionella with pneumococcal and mycoplasma pneumonias. $\mathrm{Br} J$ Dis Chest 1987, 81:133-39.

II. Marrie TJ: Mycoplasma pneumoniae pneumonia requiring hospitalization, with emphasis on infection in the elderly. Arch Intern Med 1993, I 53:488-94.

12. Marrie TJ, Poulin-Costello M, Beecroft MD, Herman-Gnjidic Z: Etiology of community-acquired pneumonia treated in an ambulatory setting. Respir Med 2005, 99:60-5.

13. Lieberman D, Schlaeffer F, Horowitz S, Horovitz O, Porath A: Mycoplasma pneumoniae community-acquired pneumonia: a review of IOI hospitalized adult patients. Respiration 1996, 63:26I-66.

14. Bochud PY, Moser F, Erard P, Verdon F, Studer JP, Villard G, Cosendai A, Cotting M, Heim F, Tissot J, et al.: Community-acquired pneumonia. A prospective outpatient study. Medicine 200I, 80:75-87B.

15. Beersma MFC, Dirven K, van Dam AP, Templeton KE, Claas ECJ, Goossens H: Evaluation of $I 2$ commercial tests and the Complement Fixation Test for Mycoplasma pneumoniae-specific immunoglobulin G (IgG) and IgM antibodies, with PCR used as the "Gold Standard". J Clin Microbiol 2005, 43:2277-85.

16. Daxboeck F, Krause R, Wenisch C: Laboratory diagnosis of Mycoplasma pneumoniae infection. Clin Microbiol Infect 2003, 9:263-73.

17. Loens K, Ursi D, Goossens H, Leven M: Molecular diagnosis of Mycoplasma pneumoniae respiratory tract infections. J Clin Microbiol 2003, 41:4915-23.

18. Ruiz M, Ewig S, Marcos MA, Martinez JA, Arancibia F, Mensa J, Torres A: Etiology of community-acquired pneumonia: impact of age, comorbidity, and severity. Am J Respir Crit Care Med 1999, 1 60:397-405.

19. Weigl JA, Puppe W, Meyer CU, Berner R, Forster J, Schmitt HJ, Zepp F: Ten years' experience with year-round active surveillance of up to 19 respiratory pathogens in children. Eur J Pediatr 2007, I 66:957-66.

20. Mills GD, Oehley MR, Arrol B: Effectiveness of beta lactam antibiotics compared with antibiotics active against atypical pathogens in non-severe community acquired pneumonia: meta-analysis. BMJ 2005, 330:456.

21. Gleason PP, Meehan TP, Fine JM, Galusha DH, Fine MJ: Associations between initial antimicrobial therapy and medical outcomes for hospitalized elderly patients with pneumonia. Arch Intern Med 1999, 159:2562-72.

22. Dudas V, Hopfel A, Jacobs R, Guglielmo B]: Antimicrobial selection for hospitalized patients with presumed communityacquired pneumonia: a survey of nonteaching US community hospitals. Ann Pharmacother 2000, 34:446-52.

23. Frei CR, Koeller JM, Burgess DS, Talbert RL, Johnsrud MT: Impact of atypical coverage for patients with community-acquired pneumonia managed on the medical ward: results from the United States Community-Acquired Pneumonia Project. Pharmacotherapy 2003, 23: I 167-74.

24. Houck PM, MacLehose RF, Niederman MS, Lowery JK: Empiric antibiotic therapy and mortality among medicare pneumonia inpatients in 10 western states: 1993, I995, and 1997. Chest 200I, I I 9:1420-26.

25. Burgess DS, Lewis JS 2nd: Effect of macrolides as part of initial empiric therapy on medical outcomes for hospitalized patients with community-acquired pneumonia. Clin Ther 2000 , 22:872-78.

26. Mandell LA, Wunderink RG, Anzueto A, Bartlett JG, Campbell GD, Dean NC, Dowell SF, File TM Jr, Musher DM, Niederman MS, et al.: Infectious Diseases Society of America/American Thoracic Society consensus guidelines on the management of com- munity-acquired pneumonia in adults. Clin Infect Dis 2007, 44(Suppl 2):S27-72.

\section{Pre-publication history}

The pre-publication history for this paper can be accessed here:

http://www.biomedcentral.com/1471-2334/9/62/prepub
Publish with Bio Med Central and every scientist can read your work free of charge

"BioMed Central will be the most significant development for disseminating the results of biomedical research in our lifetime. "

Sir Paul Nurse, Cancer Research UK

Your research papers will be:

- available free of charge to the entire biomedical community

- peer reviewed and published immediately upon acceptance

- cited in PubMed and archived on PubMed Central

- yours - you keep the copyright

Submit your manuscript here:

http://www.biomedcentral.com/info/publishing_adv.asp 